\title{
Effects of dry fog humidification on pericarp browning and quality of litchi fruit stored at low temperature
}

\author{
Lu Xiao ${ }^{1,2}$, Taotao Li ${ }^{1}$, Guoxiang J iang ${ }^{1}$, Afiya J ohn ${ }^{1,2}$, Dandan Zhang ${ }^{1}$, \\ Wenyuan $\mathrm{J} \mathrm{in}^{3}$, Xuewu Duan ${ }^{1 *}$, Yueming Jiang ${ }^{1}$ \\ (1. Guangdong Provincial Key Laboratory of Applied Botany/Key Laboratory of Post-Harvest Handling of Fruits, Ministry of Agriculture \\ and Rural Affairs/ Key Laboratory of Plant Resources Conservation and Sustainable Utilization, South China Botanical Garden, \\ Chinese Academy of Sciences, Guangzhou 510650, China; 2. University of Chinese Academy of Sciences, Beijing 100049, China; \\ 3. Suzhou Full Fortune Food Company, Suzhou 215111, China)
}

\begin{abstract}
Pericarp browning is the major cause of deterioration of harvested litchi fruit. Water loss plays a role in pericarp browning of litchi fruit. This study investigated the effects of humidification with dry fog on pericarp browning and quality of litchi fruit stored at low temperature. Litchi fruit were stored in a non-humidified cold chamber (control) or in a humidified cold room using Tabor atomizer system that generated 95\% relative humidity $(\mathrm{RH})$ without depositing water on the fruit surface at $4^{\circ} \mathrm{C}$. Control fruit stored in cold room without added humidity underwent rapid weight loss, accompanied by severe pericarp browning after $25 \mathrm{~d}$ of storage. However, slight weight loss and no obvious pericarp browning were found in humidified-fruit. Moreover, humidification maintained well the integrity of cell membrane and inhibited polyphenol oxidase activity during early storage. In addition, respiration rate was obviously inhibited in humidified-fruit compared with control fruit. This study might provide a convenient approach to reduce pericarp browning of harvested litchi fruit by humidifying the fruit using the Tabor atomizer at low temperature instead of packaging with film.
\end{abstract}

Keywords: litchi, pericarp browning, dry fog, high relative humidity, cold storage

DOI: $10.25165 /$ j.ijabe.20191204.4420

Citation: Xiao L, Li T T, Jiang G X, John A, Zhang D D, Jin W Y, et al. Effects of dry fog humidification on pericarp browning and quality of litchi fruit stored at low temperature. Int J Agric \& Biol Eng, 2019; 12(4): 192-196.

\section{Introduction}

Litchi (Litchi chinensis Sonn.) is a non-climacteric fruit with high commercial value for its white translucent aril and attractive red pericarp color. However, the fruit after harvest undergo rapid deterioration due to pericarp browning, resulting in reduced market value $^{[1]}$. Pericarp browning is the major limitation for long-term storage and transportation of the fruit ${ }^{[2]}$. Postharvest browning of litchi fruit has mainly been attributed to degradation of red pigments and oxidation of phenolics by polyphenol oxidase (PPO) and peroxidase $(\mathrm{POD})^{[3]}$. Jiang et al. $^{[3]}$ proposed that anthocyanins are hydrolyzed by anthocyanase, forming anthocyanins, which are further oxidized by PPO and/or POD. Recently, an enzyme that degrades anthocyanin was identified as vacuolar laccase, which is responsible for epicatechin-mediated anthocyanin degradation during litchi pericarp browning ${ }^{[4]}$.

Water loss plays a role in pericarp browning of harvested litchi

Received date: 2018-05-21 Accepted date: 2018-12-05

Biographies: Lu Xiao, PhD candidate, research interest: postharvest biology, Email: xiaolu@scbg.ac.cn; Taotao Li, Associate Professor, research interest: postharvest biology, Email: litaotao@scbg.ac.cn; Guoxiang Jiang, Associate Professor, research interest: postharvest biology, Email: gxjiang@scbg.ac.cn; Afiya John, PhD candidate, research interest: postharvest biology, Email: afiyajohn@hotmail.com; Dandan Zhang, Assistant Researcher, research interest: postharvest biology, Email: ddzhang@scbg.ac.cn; Wenyuan Jin, General Manager, research interest: food science, Email: szjindafu@126.com; Yueming Jiang, Professor, research interest: postharvest biology, Email: ymjiang@ scbg.ac.cn.

*Corresponding author: Xuewu Duan, Professor, research interest: postharvest, No. 723 Xingke Road, Tianhe District, Guangzhou 510650, Guangdong, China. Tel: + 86-20-37252960, Fax: + 86-20-37252831, Email: xwduan@scbg.ac.cn. fruit. Water loss results in a series of biochemical and physiological changes. Jiang and $\mathrm{Fu}^{[5]}$ reported that water loss reduces the antioxidant capacities and increases the oxidation of phenolics catalyzed by PPO and POD. Desiccation also may increase the $\mathrm{pH}$ of the cell, which alters the structure, stability and color of anthocyanins, thereby resulting in pericarp browning ${ }^{[6,7]}$. Due to the special structure of litchi fruit, it is difficult for water to be transported from pulp to pericarp to improve its moisture. Meanwhile, with ripening and senescence of the fruit, the micro-cracking appeared in the thin skin surface, which also accelerates water loss ${ }^{[8]}$. Therefore, it is crucial to prevent water loss for reducing pericarp browning and extending the shelf life of litchi fruit.

Techniques are developed to reduce water loss and control pericarp browning of litchi fruit, including modified atmosphere packaging, coating, packaging in plastic bags, styrene punnets, or moulded plastic trays wrapped in plastic ${ }^{[1]}$. However, litchi fruit are susceptible to anaerobic respiration under modified atmosphere packaging, resulting in the accumulation of ethanol and acetaldehyde $^{[9]}$. Application of coating is very costly and low efficiency for preventing pericarp browning ${ }^{[10,11]}$. Only plastic packaging has been used commercially ${ }^{[1]}$. Jiang and $\mathrm{Fu}^{[5]}$ reported that high relative humidity reduces water loss and delays pericarp of harvested litchi fruit during shelf life at $20^{\circ} \mathrm{C}$. For long-term storage in cold chamber, increasing the $\mathrm{RH}$ of the air reduces water loss of the fruit, which can be achieved by spaying water as a fine mist or by introducing steam. However, addition of free water to the system results in its condensation on cold surfaces (e.g. fruit, wall, carton), favoring fungal growth ${ }^{[12]}$. To overcome this disadvantage, it is necessary to develop an alternative approach to add the RH in the air, but deposit no free water on the fruit. 
Dry fog is defined as droplets with the sizes as small as 2 microns and consistently well below 10 micron, which can maintain a high humidity environment, without the dripping and dampness on cold surfaces. Dry fog provides a promising way to add the $\mathrm{RH}$ when storing fruits and vegetables in cold room. However, only limited information is available on application of dry fog in fruits and vegetables ${ }^{[13,14]}$. Afek et al. ${ }^{[13]}$ reported that dry fog humidification effectively reduces weight loss and holds firmness in stored potato tubers. Tabor atomizer system produces dry fog particles that rapidly evaporate before saturating or condensing on cold surface ${ }^{[13]}$. The objective of this work was to investigate the effect of the Tabor atomizer system on water loss, pericarp browning and quality of harvested litchi fruit. The result might provide a convenient, safe and effective approach to prevent moisture loss and pericarp browning of harvested litchi when stored in cold room.

\section{Materials and methods}

\subsection{Plant materials and treatments}

Litchi (Litchi chinensis Sonn. cv. Huaizhi) fruit were harvested at an $80 \%$ maturity (90 d after anthesis) with a total soluble solid content of approximately $20 \%$ from a commercial orchard and immediately transported to the laboratory. Fruit were selected for uniformity of shape, color and size. Any blemished, diseased or browned fruit were discarded. The fruit were dipped in $0.05 \%$ Sportak ${ }^{\circledR}$ (Prochloraz, Bayer, Leverkusen, Germany) as a fungicide for $3 \mathrm{~min}$ and then air dried.

A total of $60 \mathrm{~kg}$ of fruit (approximately 2400 fruit) were divided into two groups. The first group was placed in plastic crates covered with kraft paper and then stored in routine cold chamber without adding humidity at $4^{\circ} \mathrm{C}$ as the control. The humidity in the cold chamber ranged from $70 \%$ to $75 \%$. The second group was placed in plastic crates covered with kraft paper and directly stored in cold chamber equipped with Tabor atomizer system (Optiguide Controlled Humidity Ltd., Yokneam illit, Israel). The system can produce droplets with the size of less than $10 \mathrm{~m}$, behaving like a dry cloud, which resulted in no depositing water on the fruit surface. The relative humidity and temperature were set at $95 \%$ and $4{ }^{\circ} \mathrm{C}$ respectively. Each treatment was replicated three times. Weight loss, pericarp browning and quality attributes were evaluated at $5 \mathrm{~d}$ intervals during $25 \mathrm{~d}$ of storage.

\subsection{Weight loss}

The weights of the fruit used for evaluating weight loss were recorded at $5 \mathrm{~d}$ interval. Weight loss ratio (\%) = (initial weight final weight)/initial weight $\times 100 \%$.

\subsection{Pericarp browning degree}

Litchi pericarp browning degree was evaluated by the method of Ngammongkolrat et al. ${ }^{[15]}$ Pericarp tissue $(5.0$ g) from thirty fruit was ground in liquid nitrogen and homogenized in $50 \mathrm{~mL}$ of anhydrous ethanol. After centrifugation for $5 \mathrm{~min}$ at $10000 \mathrm{~g}$ and $4^{\circ} \mathrm{C}$, the absorbance at $420 \mathrm{~nm}$ of the supernatant was measured. The relative browning degree was expressed as $\mathrm{OD}_{420 \mathrm{~nm}}$ per gram of fresh weight.

\subsection{Color parameter}

The pericarp color was measured with a Konica Minolta CR-400 colorimeter (Konica Minolta Co. Ltd., Japan) in the CIE $\mathrm{L} * \mathrm{a} * \mathrm{~b}$ mode. $\mathrm{L}$ values indicated the relative lightness ranging from black to white, $\mathrm{C}$ value represented the relative color saturation that varied from dull to vivid, and hue angle referred to a color wheel, with red at an angle of $0^{\circ}$, yellow at $90^{\circ}$, green at $180^{\circ}$, and blue at $270^{\circ}$.

\subsection{Relative leakage rate}

Membrane integrity, expressed as relative leakage rate, was determined with a conductivity meter (Model DDS-11A, Shanghai Scientific Instruments). Discs were removed with a cork borer (10 $\mathrm{mm}$ in diameter) from thirty fruit. Thirty discs were rinsed three times with distilled water and then incubated in $25 \mathrm{~mL}$ of $0.3 \mathrm{M}$ mannitol in distilled water at $25^{\circ} \mathrm{C}$ for $30 \mathrm{~min}$. Subsequently, the matching batch of discs was boiled for $15 \mathrm{~min}$ and then cooled to $25^{\circ} \mathrm{C}$. The electrolyte leakages after incubation and boiling were determined as initial and total electrolyte leakage, respectively. The relative leakage was expressed as a percentage of initial to total electrolyte leakage.

\subsection{Measurement of PPO activity}

Pericarp tissues $(2.0 \mathrm{~g})$ from thirty fruit were ground in liquid nitrogen and homogenized in $20 \mathrm{~mL}$ of $0.05 \mathrm{M}$ phosphate buffer (pH 7.0) and $0.5 \mathrm{~g}$ of polyvinylpyrrolidone (insoluble) at $4^{\circ} \mathrm{C}$. After centrifugation for $20 \mathrm{~min}$ at $19000 \times \mathrm{g}$ and $4^{\circ} \mathrm{C}$, the supernatant was collected as the crude enzyme extract of the analysis of PPO activity. PPO activity with 4-methylcatechol as the substrate was assayed by the method of Jiang ${ }^{[16]}$. One unit of enzyme activity was defined as the amount that caused a change of 0.001 in the absorbance at $398 \mathrm{~nm}$ per minute. The results were expressed on a fresh weigh basis.

\subsection{Respiration rate}

The respiration rate of litchi fruit was determined by infrared gas analyzer. Fifteen fruit were sealed in an easy-lock plastic box (2.5 $\mathrm{L}$ in volume) at $25^{\circ} \mathrm{C}$ through which $\mathrm{CO}_{2}$-free air were pumped. Increases in $\mathrm{CO}_{2}$ concentration in the box were monitored for 5 min by passing the air stream through an infrared gas analyzer ( $\mathrm{Li}-6262 \mathrm{CO}_{2} / \mathrm{H}_{2} \mathrm{O}$ analyzer). Respiration rates were expressed $\mathrm{mg} \mathrm{CO}_{2} /(\mathrm{h} \cdot \mathrm{kg})$ fresh weight.

\subsection{Total soluble solids and titratable acidity}

Pulp tissues from twenty fruit were grinded by juicer and filtered with four-layer gauze. The filtrate was used for analysis of total soluble solid and titratable acidity. Total soluble solids were assayed by using a hand-held refractometer (J1-3A, Guangdong Scientific Instruments). Titratable acidity was determined by titration with $0.1 \mathrm{M} \mathrm{NaOH}$, expressed as citric acid.

\subsection{Statistical analysis}

The experiments were arranged in completely randomized design with three replicates and the data were expressed as the mean \pm SE (standard error). Data were analyzed by SPSS version 19.0. Least significant differences (L.S.D.) were calculated to compare significant effects at $5 \%$ level.

\section{Results and discussion}

Pericarp browning is the major cause of deterioration of harvested litchi fruit ${ }^{[3]}$. Postharvest technologies, such as sulfur fumigation, acid dips, fungicides, heat treatment, packaging, skin coating and modified atmosphere packaging, have been developed to reduce pericarp browning ${ }^{[1]}$. Of these treatments, sulfur fumigation is considered the most effective and practical treatment to control browning in litchi fruit ${ }^{[17]}$. Sulfur dioxide inhibits non-enzymatic formation of colorless quionine-sulfite complexes and enzymatic browning by inactivating PPO activity. ${ }^{[6]}$ Sulfur fumigation is usually applied in combination with acid dips to recover the bleached pericarp to red color ${ }^{[8]}$. Considering the potential safety issue, the quest for effective commercially alternative approaches without sulfur for postharvest litchi management is a research priority. Although packaging with plastic film has been used commercially in the storage and 
transport of litchi fruit, the application is inconvenient and vulnerable to anaerobic respiration ${ }^{[9]}$. Moreover, condensation on cold surfaces can promote fungal development.

In this study, a convenient approach was developed to reduce pericarp browning by humidifying the fruit using the Tabor atomizer system. This system produced droplets less than $10 \mathrm{~m}$ in size, behaving like a dry cloud and generated $95 \%$ relative humidity (RH) without depositing water on litchi fruit surface. As shown in Figure 1, non-humidified litchi fruit (control) exhibited obvious browning $15 \mathrm{~d}$ after storage at low temperature and severe browning at $25 \mathrm{~d}$. However, no obvious browning was observed in humidified fruit at $25 \mathrm{~d}$. To objectively evaluate the effect of dry fog humidification on pericarp browning, the browning degree was analyzed, which measured the relative browning degree of the whole fruit pericarp. As shown in Figure 2a, pericarp browning of control litchi fruit rapidly increased with increasing storage time, especially at $20 \mathrm{~d}$. However, only slight increases in pericarp browning degree were found in humidified-litchi fruit. These results were in accordance with the visual appearance (Figure 1).

In addition, several color parameters were also measured to evaluate the effect of humidification on visual appearance. Control fruit rapidly became darker, as reflected by a decrease in $\mathrm{L}$ value (Figure $2 \mathrm{~b}$ ), showed less intensive with much lower $\mathrm{C}$ value (Figure 2c), and turned more yellow, approximately the hue value of 50 (Figure 2d) during storage, compared with humidified-litchi fruit. These results indicated that dry fog humidification effectively maintained the visual quality.
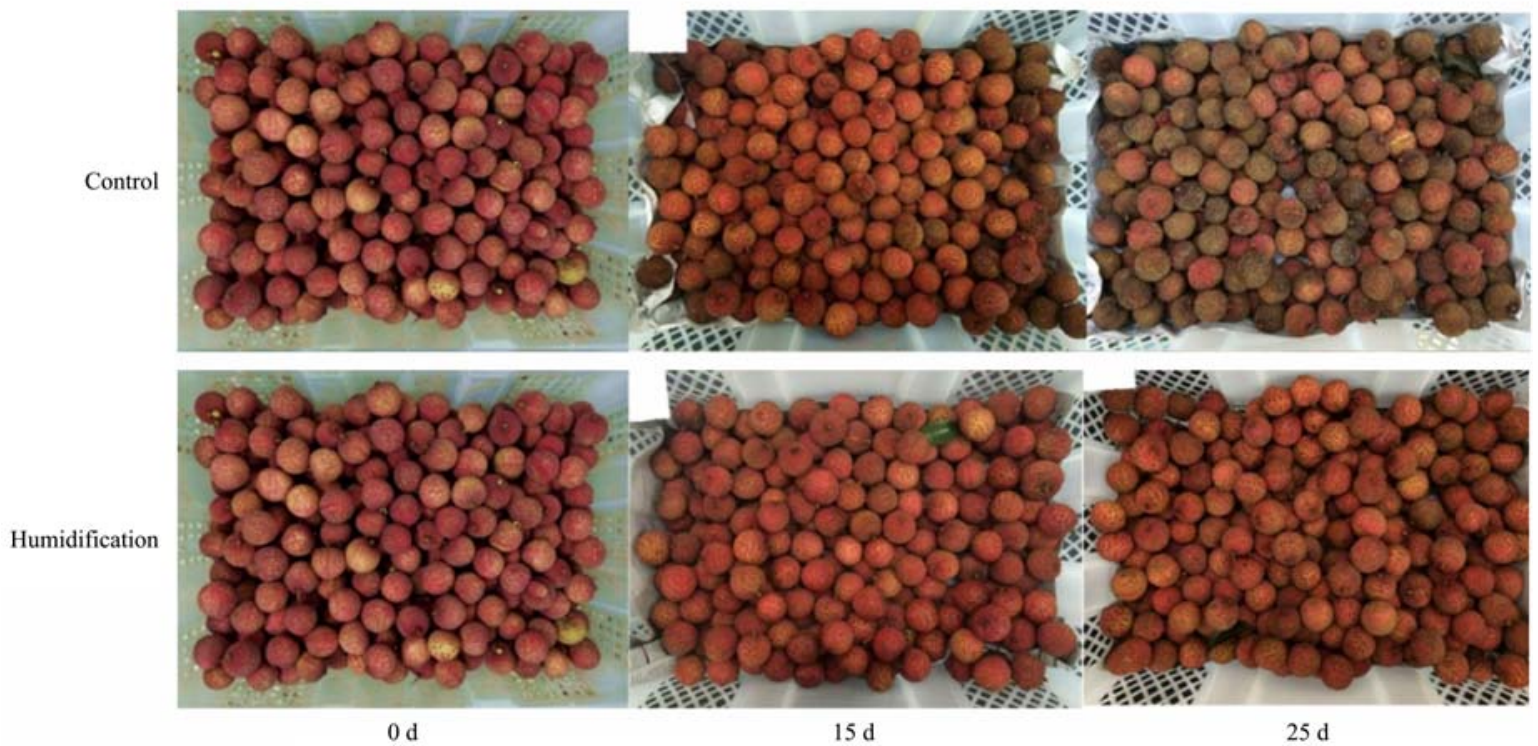

Figure 1 Visual appearance of litchi fruit after $15 \mathrm{~d}$ and $25 \mathrm{~d}$ of storage stored under different humidity conditions at $4{ }^{\circ} \mathrm{C}$

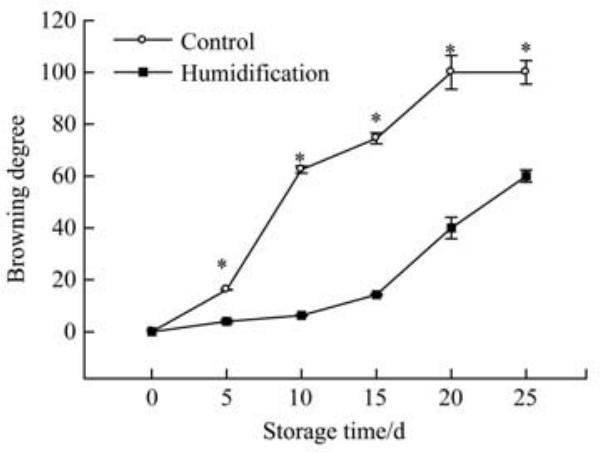

a

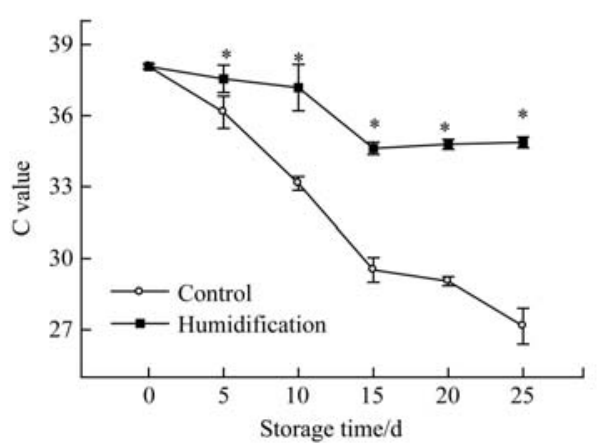

$\mathrm{c}$

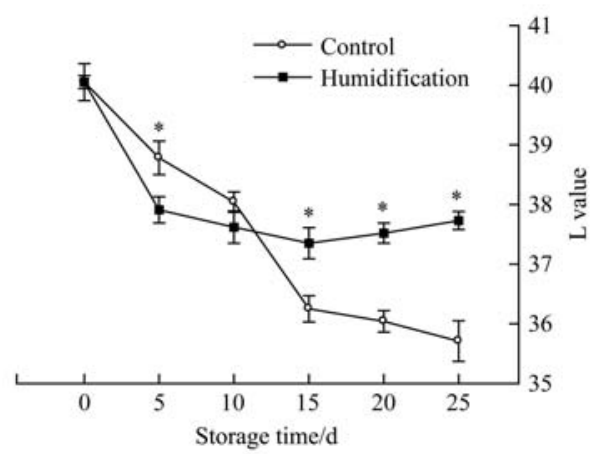

b

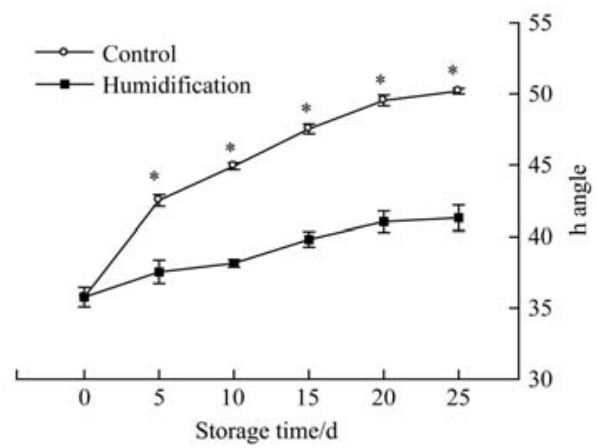

d

Note: The relative browning degree was expressed as $\mathrm{OD}_{420 \mathrm{~nm}}$ per gram of fresh weight. Each data point represents a mean \pm standard error $(n=3)$. Asterisk means a significant difference between control and humidified fruit at $5 \%$ level.

Figure 2 Effects of dry fog humidification different humidity conditions on pericarp browning degree (a), color parameter lightness (b), chroma (c) and hue angle (d) of litchi fruit during storage at $4^{\circ} \mathrm{C}$ 
Browning is thought to be due to breakdown in cellular compartmentation of enzymes and substrates, which in turn cause oxidation of phenolics, producing brown by-products ${ }^{[3]}$. Moisture is important for the maintenance of cell structure of litchi fruit ${ }^{[18]}$ and water loss results in the decompartmentation of enzymes and substrates ${ }^{[5]}$. Membrane integrity, expressed as relative leakage rate, is an important indicator of membrane integrity. Loss of membrane integrity usually occurred during tissue deterioration and senescence ${ }^{[19,20]}$. In the present study, with increased storage time at low temperature, weight loss sharply increased in the control fruit and reached $16.0 \%$ after $25 \mathrm{~d}$ of storage (Figure 3a), accompanied by the significant increase in relative leakage rate from $13.0 \%$ at $0 \mathrm{~d}$ to $44.2 \%$ at $25 \mathrm{~d}$ (Figure $3 \mathrm{~b}$ ), indicating the loss of membrane integrity. However, only slight weight losses in humidified- litchi fruit were observed after $25 \mathrm{~d}$ of storage (Figure 3a), indicating that moisture in humidified-fruit were well maintained. Furthermore, membrane integrity in humidified-litchi fruit were well maintained (Figure 3b). It is generally acknowledged that PPO is involved in enzymatic browning of harvested litchi fruit ${ }^{[21,22]}$. PPO catalyzes the oxidation of phenol to quinones and then condenses tannins to brown polymers. In the present study, PPO activity in control fruit slightly increased and then decreased. However, PPO activities in humidifiedfruit firstly decreased and then increased. During early storage, PPO activity of control fruit was higher than that of humidified-fruit (Figure 3c), implying water loss activated PPO activity. Therefore, water loss resulted in the loss of cell membrane integrity and higher PPO activity, which was beneficial in oxidation of phenolics and pericarp browning. However, humidification with dry fog effectively prevented moisture loss and pericarp browning.

Litchi is a non-climacteric fruit, which undergo vigorous respiration after harvested. Litchi fruit respiration rates tended to decrease as storage time increased (Figure 4a). Respiration rate is an excellent indicator of metabolic activity for the fruit and thus is a useful guide to the potential storage life of the produce ${ }^{[12]}$. The higher respiration rate in control fruit than in humidified fruit means more consumption of carbohydrates and shorter storage life (Figure 4a). Total soluble solids (TSS) and titratable acidity (TA) are important factors in evaluating flesh flavor and nutritive quality of litchi fruit ${ }^{[1]}$. In the present study, the contents of TSS and TA in humidified- fruit were lower than those in control fruit (Figures $4 \mathrm{~b}$ and $4 \mathrm{c}$ ). It is possible that excessive water loss in unwrapped control fruit resulted in the higher TSS and TA contents.

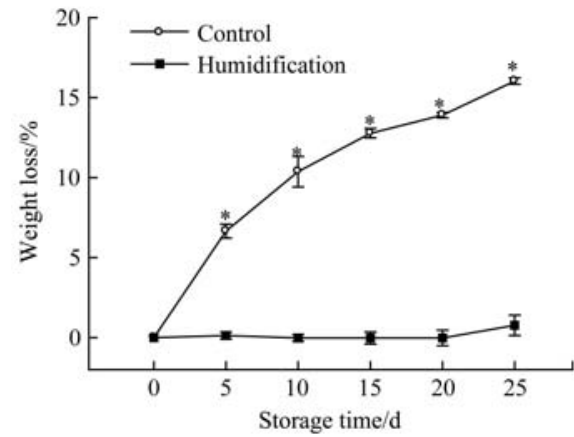

a

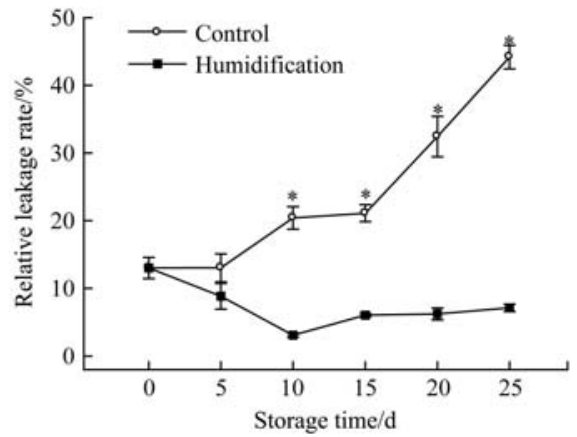

b

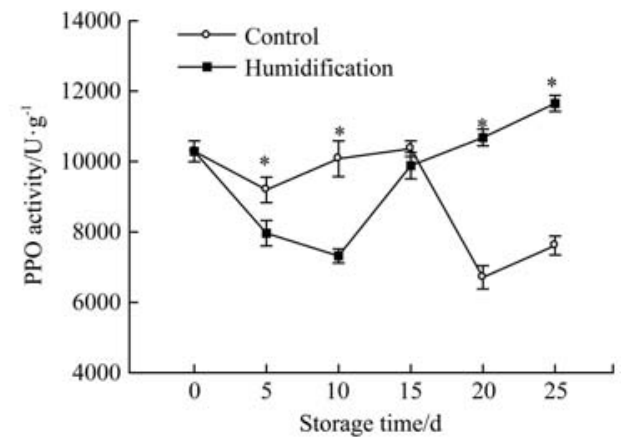

C

Note: Each data point represents a mean \pm standard error $(n=3)$. Asterisk means a significant difference between control and humidified fruit at $5 \%$ level.

Figure 3 Effects of dry fog humidification on weight loss (a), relative leakage rate (b) and PPO activity (c) of litchi fruit during storage at $4{ }^{\circ} \mathrm{C}$

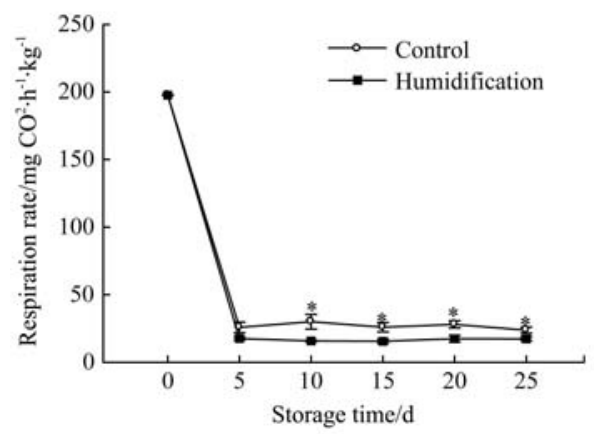

a

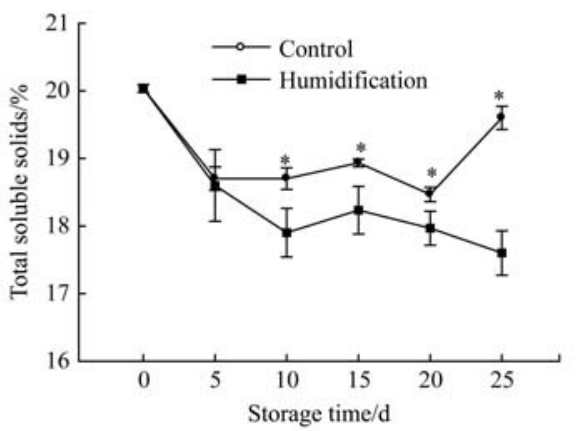

b

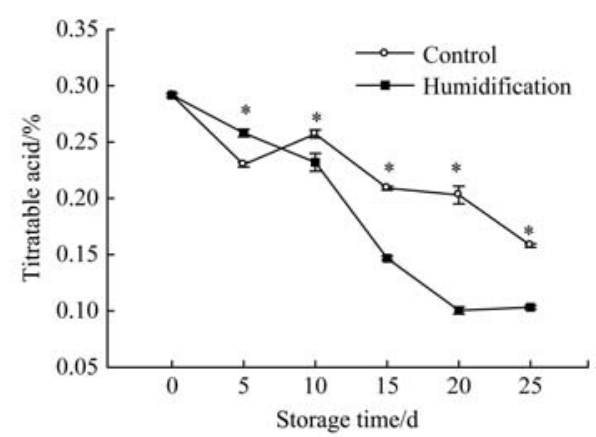

c

Note: Each data point represents a mean \pm standard error $(n=3)$. Asterisk means a significant difference between control and humidified fruit at $5 \%$ level.

Figure 4 Effects of dry fog humidification on respiration rate (a), total soluble solids (b) and titratable acid (c) of litchi fruit during storage at $4{ }^{\circ} \mathrm{C}$

\section{Conclusions}

Dry fog humidification using the Tabor atomizer system effectively inhibited water loss and pericarp browning of harvested litchi fruit stored at low temperature, which may be associated with maintenance of cell membrane integrity and inhibition of PPO activity. It could provide an effective approach to maintain visual quality of harvested litchi fruit at low temperature.

\section{Acknowledgements}

This work was supported by National Key R\&D Program of China (No. 2018YFD0401301), National Natural Science Foundation of China (Nos 31770726 and 31772041), Science and Technology Planning of Jiangsu Province (No. BZ2013004), 
Science and Technology Planning Project of Guangzhou (No. 201804020041), Agro-scientific Research in the Public Interest (No. 201303073). The work was also supported by National Botanical

Gardens, CAS.

\section{[References]}

[1] Jiang Y M, Wang Y, Song L, Liu H, Lichter A, Kerdchoechuen O, et al. Postharvest characteristics and handling of litchi fruit - an overview. Australian Journal of Experimental Agriculture, 2006; 46(12): 1541-1556.

[2] Reichel M, Triani R, Wellhoefer J, Sruamsiri P, Carle R, Neidhart S. Vital characteristics of litchi (Litchi chinensis Sonn.) pericarp that define postharvest concepts for Thai cultivars. Food and Bioprocess Technology, 2013; 6: 1191-1206.

[3] Jiang Y M, Duan X W, Joyce D, Zhang Z Q, Li J R. Advances in understanding of enzymatic browning in harvested litchi fruit. Food Chemistry, 2004; 88(3): 443-446.

[4] Fang F, Zhang X L, Luo H H, Zhou J J, Gong Y H, Li W J, et al. An intracellular laccase is responsible for epicatechin-mediated anthocyanin degradation in litchi fruit pericarp. Plant Physiology, 2015; 169(4): 2391-2408.

[5] Jiang Y M, Fu J R. Postharvest browning of litchi fruit by water loss and its prevention by controlled atmosphere storage at high relative humidity. Lebensmittel-Wissenschaft und - Technologie, 1999; 32(5): 278-283.

[6] Holcroft D M, Mitcham E J. Postharvest physiology and handling of litchi (Litchi chinensis Sonn). Postharvest Biology and Technology, 1996; 9(3): 265-281.

[7] Pang X Q, Zhang Z Q, Duan X W, Ji Z L. The effect of pH and active oxygen on the stability of anthocyanin from lychee pericarp. Acta Horticulturae, 2001; 558: 339-342.

[8] Underhill S J R, Bagshaw J, Prasad A, Zauberman G, Ronen R. The control of lychee (Litchi chinensis Sonn.) postharvest skin browning using sulphur dioxide and low pH. Acta Horticulturae, 1992; 321: 732-741.

[9] Pesis E, Dvir O, Feygenberg O, Arie R B, Ackerman M, Lichter A. Production of acetaldehyde and ethanol during maturation and modified atmosphere storage of litchi fruit. Postharvest Biology and Technology, 2002; 26(2): 157-165.

[10] Kumari P, Barman K, Patel V B, Siddiqui M W, Kole B. Reducing postharvest pericarp browning and preserving health promoting compounds of litchi fruit by combination treatment of salicylic acid and chitosan.
Scientia Horticulturae, 2015; 197: 555-563.

[11] Lin B F, Du Y M, Liang X Q, Wang X Y, Wang X H, Yang J H. Effect of chitosan coating on respiratory behavior and quality of stored litchi under ambient temperature. Journal of Food Engineering, 2011; 102(1): 94-99.

[12] Wills R, McGlasson B, Graham D, Joyce D. Postharvest: An introduction to the physiology \& handling of fruit, vegetables \& ornamentals. CAB International, Wallingford Oxon, 1998.

[13] Afek U, Orenstein J, Nuriel E. Using the tabor atomizer system to maintain weight and firmness in stored potato tubers. American Journal of Potato Research, 2000; 77(3): 203-205.

[14] Hung D V, Tanaka F, Uchino T, Hiruma N. Using nanomist humidifier to maintain postharvest quality of fig (Ficus carica L.) fruit in high humidity sotrage environment. Journal of the Faculty of Agriculture, 2011; 56(2): 361-365.

[15] Ngammongkolrat A, Moutounet M, Pech J C. Pulp browning of french prunes-methods of measurement and types of reactions involved. Sciences des Aliments, 1985; 5: 393-405.

[16] Jiang Y M. Role of anthocyanins, polyphenol oxidase and phenols in lychee pericarp browning. Journal of the Science of Food and Agriculture, 2000; 80(3): 305-310.

[17] Ray P K, Ruby R, Singh S K. Effect of sulphur dioxide fumigation and low temperature storage on post-harvest browning and quality of litchi fruits. Journal of Food Science and Technology, 2005; 42(3): 226-230.

[18] Reichel M, Wellhofer J, Triani R, Sruamsiri P, Carle R, Neidhart S. Postharvest control of litchi (Litchi chinensis Sonn.) pericarp browning by cold storage at high relative humidity after enzyme-inhibiting treatments. Postharvest Biology and Technology, 2017; 125: 77-90.

[19] Huang X M, Wang H C, Yuan W Q, Lu J M, Yin J H, Luo S, et al. A study of rapid senescence of detached litchi: Roles of water loss and calcium. Postharvest Biology and Technology, 2005; 36(2): 177-189.

[20] Sun J, Li C B, Prasad K N, You X R, Li L, Liao F, et al. Membrane deterioration, enzymatic browning and oxidative stress in fresh fruits of three litchi cultivars during six-day storage. Scientia Horticulturae, 2012; 148(1): 97-103.

[21] Mishra B B, Kumar S, Wadhawan S, Hajare S N, Saxena S, More V, et al. Browning of litchi fruit pericarp: role of polyphenol oxidase, peroxidase, phenylalanine ammonia lyase and effect of gamma radiation. Journal of Food Biochemistry, 2012; 36(5): 604-612.

[22] Wang J, Liu B, Xiao Q, Li H, Sun J. Cloning and expression analysis of litchi (Litchi Chinensis Sonn.) polyphenol oxidase gene and relationship with postharvest pericarp browning. Plos One, 2014; 9(4): e93982. 